\title{
Prevention and treatment of hand oedema after stroke
}

Citation for published version (APA):

Kuppens, S. P. M., Pijlman, H. C. P., Hitters, W. M. C. G., \& van Heugten, C. M. (2014). Prevention and treatment of hand oedema after stroke. Disability and Rehabilitation, 36(11), 900-906.

https://doi.org/10.3109/09638288.2013.824031

Document status and date:

Published: 01/01/2014

DOI:

10.3109/09638288.2013.824031

Document Version:

Publisher's PDF, also known as Version of record

Document license:

Taverne

Please check the document version of this publication:

- A submitted manuscript is the version of the article upon submission and before peer-review. There can be important differences between the submitted version and the official published version of record.

People interested in the research are advised to contact the author for the final version of the publication, or visit the DOI to the publisher's website.

- The final author version and the galley proof are versions of the publication after peer review.

- The final published version features the final layout of the paper including the volume, issue and page numbers.

Link to publication

\footnotetext{
General rights rights.

- You may freely distribute the URL identifying the publication in the public portal. please follow below link for the End User Agreement:

www.umlib.nl/taverne-license

Take down policy

If you believe that this document breaches copyright please contact us at:

repository@maastrichtuniversity.nl

providing details and we will investigate your claim.
}

Copyright and moral rights for the publications made accessible in the public portal are retained by the authors and/or other copyright owners and it is a condition of accessing publications that users recognise and abide by the legal requirements associated with these

- Users may download and print one copy of any publication from the public portal for the purpose of private study or research.

- You may not further distribute the material or use it for any profit-making activity or commercial gain

If the publication is distributed under the terms of Article $25 \mathrm{fa}$ of the Dutch Copyright Act, indicated by the "Taverne" license above, 


\title{
Disability and Rehabilitation
}

\section{Prevention and treatment of hand oedema after stroke}

\author{
Stefanie P. M. Kuppens, Hanneke C. P. Pijlman, Minou W. M. G. C. Hitters \& \\ Caroline M. van Heugten
}

To cite this article: Stefanie P. M. Kuppens, Hanneke C. P. Pijlman, Minou W. M. G. C. Hitters \& Caroline M. van Heugten (2014) Prevention and treatment of hand oedema after stroke, Disability and Rehabilitation, 36:11, 900-906, DOI: 10.3109/09638288.2013.824031

To link to this article: https://doi.org/10.3109/09638288.2013.824031

曲 Published online: 19 Aug 2013.

Submit your article to this journal $\pi$

Џlll Article views: 808

Q View related articles $\sqsubset$

View Crossmark data

Citing articles: 1 View citing articles $\longleftarrow$ 


\title{
Prevention and treatment of hand oedema after stroke
}

\author{
Stefanie P. M. Kuppens ${ }^{1}$, Hanneke C. P. Pijlman ${ }^{1}$, Minou W. M. G. C. Hitters ${ }^{1}$, and Caroline M. van Heugten ${ }^{2}$ \\ ${ }^{1}$ Rehabilitation Centre Blixembosch, Libra Rehabilitation \& Audiology, Eindhoven, the Netherlands and ${ }^{2}$ Department of Neuropsychology \& \\ Psychopharmacology, School for Mental Health and Neuroscience, Maastricht University, Maastricht, the Netherlands
}

\begin{abstract}
Purpose: As there is no evidence for a specific treatment for post-stroke-induced hand oedema, rehabilitation centre Blixembosch formalized a best practice protocol. We investigated whether the Blixembosch hand oedema protocol is usable in daily practice and leads to lower incidence (prevention) and shorter duration (treatment) compared with care as usual. Methods: In a nonrandomised comparative trial, we investigated 206 post-stroke patients admitted to two Dutch rehabilitation centres. Hand volumes were measured at least bi-weekly using a volumeter. Treatment was started according the protocol (Blixembosch) or following care as usual (Leijpark). Usability was assessed with a survey among professionals. Results: In the Blixembosch group, $16 \%$ developed oedema after admission, compared with $21 \%$ in the control group $(p=0.019)$. Average duration of oedema (both developed before and after admission) was 6.5 weeks in the Blixembosch group compared with 3.1 weeks in the control group $(p=0.000)$. Professionals were positive about the protocol. Conclusion: The study showed that the protocol is usable in daily practice and has a small beneficial effect on hand oedema incidence rates compared with care as usual. The negative effect on duration of hand oedema could also be caused by the difference in prognosis between the two groups.

\section{> Implications for Rehabilitation}

Hand oedema after stroke:

- Hand oedema often appears early after stroke.

- Preventive measures seem to reduce the incidence of hand oedema and should be promoted also in admitting hospitals.

- Age and reduced hand motor function are related to incidence of hand oedema.
\end{abstract}

Keywords

Hand oedema, prevention, rehabilitation, stroke, treatment

History

Received 30 October 2011

Revised 17 March 2013

Accepted 8 July 2013

Published online 19 August 2013

\section{Introduction}

Oedema of the paretic hand is often seen in patients with poststroke hemiplegia. It is a serious problem which could lead to joint stiffness, pain and disuse of the hand [1]. Stroke patients with oedema have significantly lower scores on measurements of arm disability [5].

Many aspects of post-stroke hand oedema are still unclear. Etiologic explanations differ widely. There is more controversy than consensus on the causative factors of hand oedema, but disturbances in lymphatic drainage, decreased muscle tone and an impaired muscle pump function have been suggested [2-5]. Incidences vary from $16 \%$ to $82.8 \%$ due to differences in definition and measurement [6]. Volumetric assessment appears to be the most suitable measurement method [7].

Various preventive and treatment regimens have been advocated, although clear evidence about effectiveness of these regimes is lacking. Preventive measures such as elevation of the

Address for correspondence: Stefanie Kuppens, Rehabilitation Centre Blixembosch, Libra Rehabilitation \& Audiology, PO Box 1355, 5602 BJ, Eindhoven, the Netherlands. Tel: +31402642742. E-mail: s.kuppens@ libranet.nl arm at rest, encouragement of active movement and trauma prevention by instruction of patients and family, are used in clinical practice; however, no effectiveness of these preventive strategies has been proven [8].

Many treatment methods are used for the reduction of hand oedema in stroke patients in clinical practice. Hardly any experimental studies have been conducted and no treatment method has yet proven its advantage over other methods. The use of a hand/wrist orthosis reduced pain but showed no effect on oedema $[9,10]$. Cold water application (cryotherapy) was evaluated in one study without a control group; no positive effects could however be attributed to this intervention [11]. Intermittent compression therapy was evaluated in one effect study which showed no reduction of hand volume [12]. There are no studies which evaluated the effects of continuous compression therapy in stroke patients. Continuous passive motion was investigated in two limited studies and showed no clinically relevant reduction of oedema [2,13]. Neuromuscular stimulation showed some short-term effects on hand oedema in severely affected stroke patients, but further research is needed to investigate long-term effectiveness $[4,14,15]$.

As there is no evidence for a specific treatment on the basis of large-scale, high-quality randomized controlled trials, an 
evidence-based approach cannot be followed and therefore rehabilitation centres use a "best practices" approach where methods are selected based on a rigorous review of the literature, staff experience, practical use and lower quality effectiveness studies.

The Rehabilitation Centre Blixembosch in the Netherlands formalized their "best practices" in a protocol including both prevention and treatment measures for hand oedema. The protocol ensures a uniform approach of diagnosis and treatment methods. The protocol consists of seven preventive measures and five treatment methods mostly used in clinical practice, found by exploration of literature, and selected on practicability, despite the lack of clear evidence for effectiveness because this is lacking. Preventive methods are mostly related to careful inspection and stimulating active movement of the arm and hand. Treatment methods consist of an orthosis, both in terms of prevention and short-term effects in reducing oedema [10], cryotherapy to stimulate vasoconstriction [11] and compression therapy to stimulate the muscle pump function [12]. Although this protocol has been used for several years, a formal evaluation has not yet been made.

The objective of this study was to determine whether the Blixembosch best practices protocol is usable in daily clinical practice and leads to lower incidence rates (prevention) and shorter duration of hand oedema (treatment) compared with care as usual.

\section{Methods}

\section{Design}

The study used a prospective non-randomised comparative design in which patients in two rehabilitation centres were compared in terms of incidence rates and duration of hand oedema. Measurements started within 1 week after admission to the rehabilitation centre and were conducted every week or every 2 weeks (depending on the presence of hand oedema) until discharge from inpatient rehabilitation which is on average 3 months later. Final measurements were performed 8 weeks after discharge when the patient was receiving outpatient rehabilitation.

\section{Participants}

Patients were recruited between August 2008 and October 2010 from the inpatient department of Rehabilitation Centre Blixembosch (Blixembosch group) and Rehabilitation Centre Leijpark (control group) in the Netherlands. All consecutive patients with a first stroke were included. Exclusion criteria were age below 18, the presence of fracture, trauma, amputation, thrombophlebitis and infection of an upper limb. Co-morbidity which causes hand oedema such as mastectomy, nephrotic syndrome, albumin level below $3.2 \mathrm{~g} / \mathrm{dl}$, liver cirrhosis, unbalanced congestive heart failure and Complex Regional Pain Syndrome type 1 and 2 were also a reason for exclusion. Furthermore, patients with diagnosed Shoulder Hand Syndrome (SHS) - using criteria from Tepperman [16] were excluded from the treatment protocol for hand oedema because the rehabilitation centre uses a separate protocol for treatment of SHS in which a distinction is made between steps for probable and definite SHS based on the Tepperman criteria. In the preventive steps SHS is taken into account.

\section{Procedure}

The treating medical physician informed the patients at admission to the rehabilitation centre about the study. Written informed consent for participation was obtained from the patients or, in the case of cognitive impairment, from their relatives. Hand volumes were measured within two weeks after admission followed by a measurement every second week, at the same day and time by skilled occupational therapists until discharge. If hand oedema was present, the frequency of the hand volume measurements was increased to a weekly measurement. Presence of Shoulder Hand Syndrome was assessed at the same moment. In addition, the degree of hand function was assessed by skilled occupational therapist at three moments: in the week of admission, at discharge and 8 weeks after discharge.

Demographic and injury-related characteristics were retrieved from the patients' medical file. After the final measurement, all involved staff of the Blixembosch group provided feedback on the usability aspects of the protocol through a written usability questionnaire which was sent to them by mail.

The study protocol received approval by the local research committee.

\section{Measurements}

Hand volumes were measured using a volume meter, as designed by Brands and Wood [17]. It measures the amount of water displaced by the hand [1]. All patients were tested in a sitting position. Water temperature was kept between $20^{\circ} \mathrm{C}$ and $30^{\circ} \mathrm{C}$. Both hands were immersed after each other in the water-filled volume meter until the stop dowel rested between the web of the middle and ring finger. The overflow was weighted using an electronic scale.

The volumeter score was calculated by expressing the difference in overflow between the paretic hand and the non-paretic hand as a percentage of the volume of the non-paretic hand: $\left.[(\mathrm{Vph}-\mathrm{Vnph}) / \mathrm{Vnph})^{*} 100\right]$. This percentage was adjusted for mean differences in right and left hand volumes in healthy people [18]. An arbitrary cut-off point of $2 \mathrm{SD}$ of the population score was chosen as a threshold for assuming the presence of oedema. Correction factors and cut-off point were taken from a study about volumetric assessment of hand oedema [7]. Hand oedema was scored as present or absent. Measuring hand oedema using volumetric assessments appeared to be more accurate than visual inspection by therapists [7]. The hand volumes were registered in an electronic spreadsheet immediately after measurement. The spreadsheet was designed in such a way that a treatment advice was given on the basis of the obtained scores.

To rate the degree of hand function impairment, the Utrecht Arm/Hand Test (UAT) was used [19]. This test reflects the stages of motor function recovery of arm/hand after stroke and has a minimum score of 0 (complete paralysis) and a maximum of 7 (clumsy hand). The inter-rater and intra-rater reliability of the UAT are excellent (weighted kappa 0.98-0.99); the UAT has high criterion validity $(0.73<\mathrm{r}>0.94)$; and the responsiveness is very good [19].

Usability of the hand oedema protocol was determined using a written questionnaire consisting of 19 multiple-choice questions and 12 open questions on four topics (prevention, intervention, volume measurement and registration). Questions were asked about preventive and treatment aspects, usability of the hand volume meter and the usability of the spreadsheet for data collection on volume measurement. As the protocol was not used in the control group, the questionnaire was only sent to rehabilitation professionals involved in the study in the Blixembosch group.

\section{Intervention}

In the Blixembosch group, the preventive and the treatment methods are described in the protocol. The preventive measures are presented in Table 1. The treatment regime consists of a progressive scheme with five steps to follow (Figure 1). Every step takes minimally two weeks. As long as the oedema increases, 
Table 1. Preventive measures.

\section{Preventive measures}

Check on oedema indications and range of movement of arm joints by treated therapists three times a week.

Ensure elevation of the affected arm/hand at rest.

Attention to careful active and passive movement of the arm/hand and encourage good posture to prevent minor trauma. Instruction to medical and nursing staff and the patient.

Check for subluxation and pain of the shoulder. In case of subluxation: use arm bandage and supporting measures.

In case of perceptual deficits such as hemi-inattention, try to have the patient focus on the affected arm/hand.

Encourage active movement and specific hand mobility exercises individually or in a training group.

Inform the family on all preventive measures.

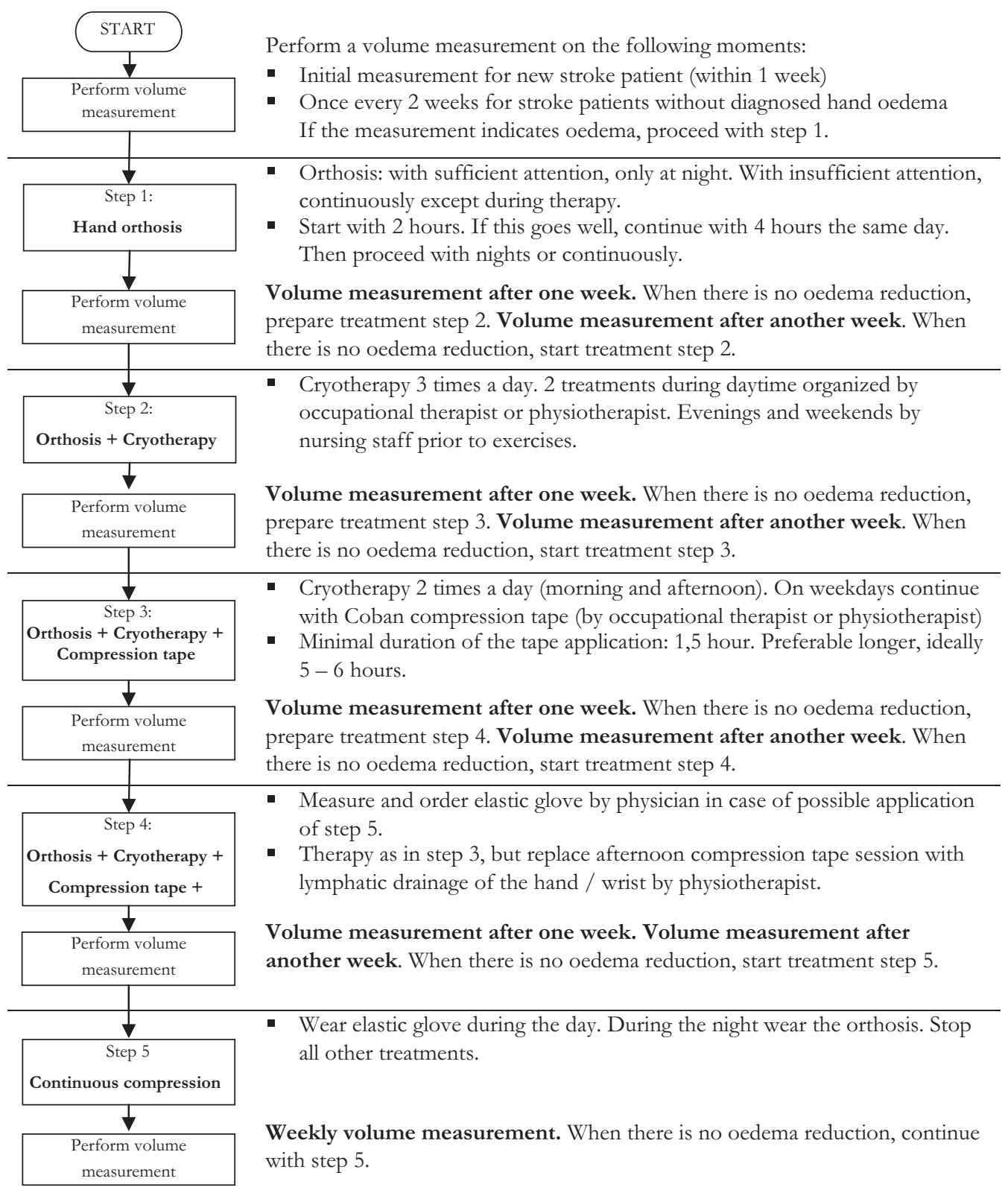

Figure 1. Treatment steps (complete overview).

a higher step is selected. For example: once hand oedema is considered to be present, step 1 will start. If after two weeks the oedema is still present and/or increasing, step 2 will start. Once the oedema reduces, treatment is phased out.

Treatment was offered according to the protocol in the Blixembosch group and following care "as usual" in the control group. Care as usual was not standardized and offered on the basis of trial and error and preferences of the therapists involved. Intervention strategies were not adapted on the basis of standardized hand volume measurements. Treatment decisions were based on clinical impression. The choice for a specific intervention varied across individuals. Most patients with hand oedema in the control group used an elevation sling. Other common methods in the control group were the use of 
Figure 2. Flow of participants.
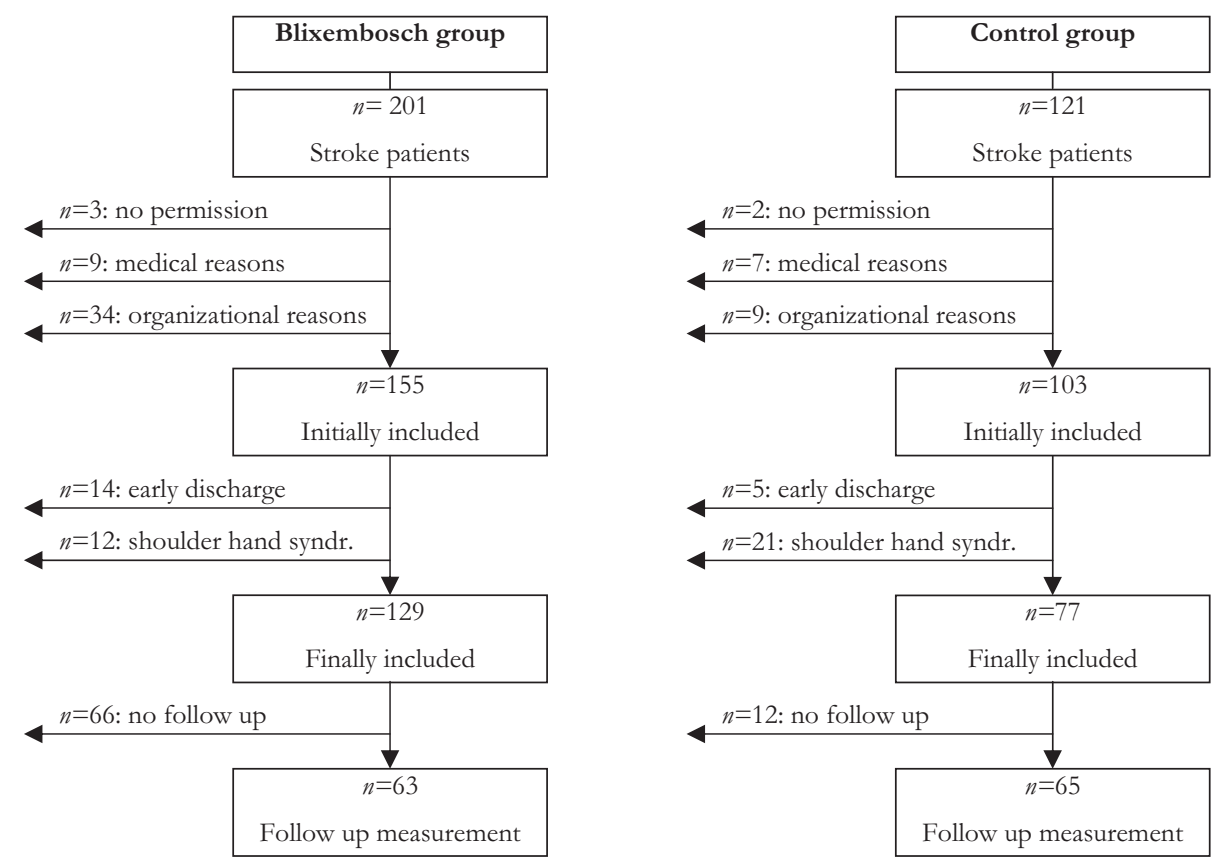

compression tape for wrapping the hand and fingers and splinting by a realignment orthosis.

\section{Data analyses}

All measurement records were represented in a spreadsheet and transferred to SPSS. Oedema duration was calculated by counting for each oedema patient the total number of weeks that oedema was present. To our surprise, hand oedema appeared to show variable patterns: oedema could be absent for 1 week and appeared to be present again at the next measurement. Variations between measurements were taken as random or measurement errors; oedema had to be measured at least for two consecutive assessments in order to be counted as present. This coincides with the choice of treatment steps in the protocol which was also made every two weeks. Mean incidence, duration and standard deviations of oedema were calculated using descriptive statistics. Groups were compared using a chi-square test for non-parametric testing and a t-test for continuous variables. When oedema was present at the initial measurement, "hospital acquired oedema" was assumed as opposed to "rehabilitation centre acquired oedema' in case the oedema was not present at admission but developed during the rehabilitation period. UAT scores were compared for both locations to determine population differences. Data on gender, UAT, dominant hand, location and presence and duration of oedema were explored using correlation analyses. The usability questionnaire was analysed using a combination of descriptive statistics and qualitative description of responses. SPSS version 18.0 (SPSS Inc., Chicago, IL) for Windows was used; alpha was set at 0.05 .

\section{Results}

The flow of participants through the study is presented in Figure 2. In the Blixembosch group, more patients were excluded for organizational reasons. Main causes were the limited capacity for measurements, holiday effects and delayed training of new team members. Also remarkable is the higher number of patients with shoulder hand syndrome in the control group and the higher number of early discharged patients in the Blixembosch group. Of all finally included patients, the follow-up measurement was done in $49 \%$ for the Blixembosch group and $84 \%$ for the control group.
The Blixembosch group and control group were comparable with regard to gender, hemisphere of stroke, type of stroke and dominant hand (Table 2). In the Blixembosch group, significantly more patients were found with functional motor impairment indicated by a low score on the UAT test, both at admission $(p<0.01)$, and discharge $(p<0.01)$, but not at follow-up. Both groups were also significantly different with regard to age: Blixembosch group 60.1 years (SD 9.5), control group 55.2 years (SD 11.5) $(p<0.01)$.

\section{Incidence of hand oedema}

According to our definition of hand oedema, in 64 patients (64/ $129 ; 50 \%)$ of the Blixembosch group oedema was present compared to $27(27 / 77 ; 35 \%)$ of the control group $(p<0.01)$. Hospital-acquired oedema was present at the initial measurement in 43 patients $(33 \%)$ in the Blixembosch group, compared to 11 patients $(14 \%)$ in the control group $(p<0.01)$. In 21 of the patients (16\%) of the Blixembosch group, oedema was present after admission - assumed as rehabilitation centre acquired oedema compared to $16(21 \%)$ in the control group $(p<0.05)$.

\section{Duration of hand oedema}

Mean time of hand oedema in the Blixembosch group was 6.5 weeks (SD 5.5), compared to 3.1 weeks (SD 2.5) $(p<0.01)$ in the control group. For patients with rehabilitation centre acquired oedema, mean duration in the Blixembosch group was 4.9 weeks (SD 4.6), compared to 1.8 weeks (SD 1.6) in the control group $(p<0.01)$.

For patients with hospital acquired oedema, mean duration in the Blixembosch group was 7.3 weeks (SD 5.8), compared to 5.0 weeks (SD 2.4) in the control group; this difference was not significant.

\section{Usability}

The survey was completed by 17 respondents (five physicians, three occupational therapists, two physiotherapists, five nurses, two support staff). Respondents only answered those questions which were related to issues they had dealt with during the study period. 
Table 2. Patient characteristics.

\begin{tabular}{lcc}
\hline Characteristics & Blixembosch & Control \\
\hline Sex, $n(\%)$ male & $82(64)$ & $53(69)$ \\
Age (years), mean (SD) & $60.1(9.5)$ & $55.2(11.5)$ \\
Hemisphere of stroke, $n$ (\%) left & $74(57)$ & $40(52)$ \\
Type of stoke, & & $54(70)$ \\
$\quad n(\%)$ ischaemic & $91(71)$ & $23(30)$ \\
$\quad n(\%)$ haemorrhagic & $38(29)$ & $69(90)$ \\
Dominant hand, $n$ (\%) right & $115(89)$ & $77(5.18)(2.77)$ \\
UAT score at admission, $n$ (mean) (SD) & $128(3.57)(3.04)$ & $74(5.47)(2.58)$ \\
UAT score at discharge, $n$ (mean) (SD) & $118(4.41)(2.95)$ & $65(5.54)(2.64)$ \\
UAT score 8 weeks after discharge, $n$ (mean) (SD) & $63(4.67)(2.83)$ & $7.1(5.3)$ \\
Time between stroke and first measurement (weeks), mean (SD) & $5.7(5.6)$ & \\
\hline
\end{tabular}

Table 3. Incidence and duration of hand oedema.

\begin{tabular}{lcc}
\hline Variable & Blixembosch group & Control group \\
\hline Presence of oedema & $50 \%$ & $35 \%$ \\
Presence of oedema before admission(hospital acquired) & $33 \%$ & $14 \%$ \\
Presence of oedema after admission(rehabilitation acquired) & $16 \%$ & $21 \%$ \\
Duration of oedema in weeks & $6.5(5.5)$ & $3.1(2.5)$ \\
Duration of oedema before admission(hospital acquired) & $7.3(5.8)$ & $5.0(2.4)$ \\
Duration of oedema after admission(rehabilitation acquired) & $4.9(4.6)$ & $1.8(1.6)$ \\
\hline
\end{tabular}

Preventive measures were found clearly described and easy to follow by $82 \%$ of the respondents. Seventy-three percent of the respondents found treatment methods were clearly defined for each treatment step. The survey showed several issues related to the volume measurements. Presence of spasm, shoulder pain and hypertonic arm or hand often led to less accurate and more time-consuming measurements. Respondents thought the measurement was not stressful for the majority of the patients. All respondents found the electronic registration form easy to use. The treatment advice provided by this form was almost always followed.

The registration of measurements showed that the initial measurement at admission was too late ( $>2$ weeks) in $29 \%$ of the patients. Sixteen percent of the patients missed more than one measurement. The survey to assess usability listed as main reasons delayed inclusion of eligible patients and miscommunication between scheduling staff and treating therapists. Hand volume measurements were scheduled during a weekly consultation hour staffed by two therapists. The survey showed that with an average of 12 stroke patients in a week, the total measurement effort was approximately 4 hours per week.

The registration showed that treatment steps from the protocol were followed in $77 \%$ of the patients. Main reason for deviations which were mentioned in the usability survey was the team deciding on a different treatment method. From all patients with diagnosed hand oedema (64), nine patients were not treated for several reasons, such as refusal of treatment, early discharge or disappearance of the oedema before treatment started. Step 1 (orthosis) was used for 55 patients, 12 patients continued with step 2 (cryotherapy), 6 patients continued with step 3 (compression tape) and 3 patients continued with step 4 (manual drainage). No patients reached step 5 (elastic glove). The survey showed that step 1 (orthosis) was quick and easy to follow. For step 2 (cryotherapy), several issues were reported: scheduling problems caused a delay, the actual given therapy was diverse and timeconsuming and for some patients the method was uncomfortable or painful. For the other steps, too little patients were involved to conclude on the usability of these steps.

\section{Explorative relationships}

A strong significant correlation was found between UAT at admission and duration of oedema $(-0.53 ; p<0.01)$, indicating that a lower UAT at admission is associated with longer duration of oedema. A significant correlation was found between age and incidence of hospital acquired oedema $(-0.16 ; p<0.05)$ and duration of oedema $(0.14 ; p<0.05)$, indicating that older patients have a higher incidence and a longer duration of oedema. Oedema incidence and duration did not correlate significantly with sex, type of stroke or hemisphere of stroke.

\section{Discussion}

In this study, we investigated the usability and the effect of the preventive and treatment steps of a best practice protocol in a nonrandomised comparative group design. The results need to be interpreted with caution because the two groups unfortunately appeared to differ in terms of age and hand function which both influence the prognosis after stroke. Despite these shortcomings, this is the first study to study oedema in a longitudinal perspective with repeated measurements.

We used the incidence rates for rehabilitation centre acquired oedema to determine the effectiveness of the preventive measures from the protocol. Comparison of these incidence rates showed that the Blixembosch group had a significantly lower rate $(16 \%)$ than the control group $(21 \%)$. This result suggests that the preventive measures from the protocol are slightly more effective than the "care as usual" measures from the control group. While the Blixembosch group had the worst prognosis (i.e. higher age and lower UAT scores), but the incidence rate was significantly lower, the preventive measures indeed seem to be effective.

The majority of the patients developing hand oedema were already diagnosed with hand oedema at admission to the rehabilitation centre: $26 \%$ of all patients developed hospital acquired oedema where $18 \%$ of all patients developed rehabilitation centre acquired oedema. The significant number of patients with hospital acquired oedema suggests that the promotion of 
preventive measures in admitting hospitals could be even more important than the promotion in the rehabilitation centres.

For the hospital acquired oedema, a significant difference was found between both centres. As each rehabilitation centre has its own referring hospitals, the most probable explanation is a difference in focus on preventive measures at these hospitals. Furthermore, this is a strong indication that preventive measures can make a difference in oedema incidence rates and is definitely a very interesting subject for further investigation.

The incidence in both groups is higher than the $33 \%$ reported in an earlier study [6]. This could be caused by the higher measuring frequency in our study (once every 2 weeks compared with once at admission and once before discharge).

We used the mean duration of oedema to determine the effectiveness of the treatment measures from the protocol. Comparison of oedema duration showed a significantly longer duration in the Blixembosch group than the control group. Looking only at patients with rehabilitation centre acquired oedema, mean duration in the Blixembosch group was still significantly longer than the control group. Evidently, this result needs to be interpreted while taking the difference in age and hand function between the groups into account. The longer duration of oedema could also be caused by the fact that the Blixembosch group had the worst prognosis which was shown by the relationships between duration of oedema and age and hand function.

In the Blixembosch group, the majority of the patients with hand oedema were treated with a realignment orthosis (55). Only 12 patients received additional treatment with cryotherapy, compression tape and manual drainage. The study was not designed to measure the effectiveness of a single treatment method. Therefore, although many patients showed oedema reduction after orthosis treatment, normal drift of hand oedema could also have contributed.

The usability questionnaire showed no major issues related to the feasibility of the protocol. The hand orthosis (step 1) appeared to be a simple and quickly available method to implement. The other steps were used infrequently, so no general conclusion can be drawn on the usability. However, considering the few patients involved in steps 2 till 5 and the difficulties reported for step 2, it is questionable if the protocol needs to describe these steps. An individual approach for each patient when an orthosis is not sufficient might be more practical.

\section{Study limitations}

The Blixembosch group had a larger number of admitted patients who already had hand oedema which could be more difficult to treat. Also mean UAT scores showed the Blixembosch group patient population had less motor function at admission and were older. These differences are most probably due to differences in referral patterns. Age and UAT score at admission were found to be related with incidence and duration of hand oedema. This provides an opportunity to differentiate when promoting preventive measures and performing volume measurements.

Furthermore, in both centres, the study increased the focus on preventive and treatment measures. For the control group, this could have led to more attention on hand oedema than before. In addition, some of the treatment methods were equal in both groups as both centres used orthoses and compression therapy.

As this was the first study to measure hand volumes repeatedly, a solution for the unexpected variable pattern of oedema had to be found. More studies are needed to verify whether this variable pattern is normal in a rehabilitation stroke population and should therefore be taken into account in future studies.
Finally, some methodological limitations should be mentioned. Patients were lost to follow-up, mainly due to organizational reasons. The measurements were done by team members who were not independent of the treatment given, which might have influenced the outcome. And the use of a comparative design instead of a randomized controlled design raises potential bias. However, because the evidence based on hand oedema is only very limited, we do believe our data are of added value.

\section{Conclusion}

The study showed that the protocol is usable in daily practice and has a small beneficial effect on hand oedema incidence rates compared with care as usual. The negative effect on duration of hand oedema could also be caused by the difference in prognosis between the two groups.

The study showed $44 \%$ of the patients developed hand oedema, of which the majority acquired oedema already before admission to the rehabilitation centre. Focus on preventive measures in admitting hospitals is therefore important.

Although the protocol in its current format did not lead to a reduction of hand oedema, the results can be used as a baseline for further studies on the effectiveness of both preventive measures and treatment methods.

\section{Declaration of interest}

The authors report no declarations of interest.

\section{References}

1. Flowers KR. Managing edema. In: Hunter JM, Mackin EJ, Schneider LH, eds. Rehabilitation of the hand. 2nd ed. St. Louis: C.V. Mosby; 1984:87-8.

2. Giudice ML. Effects of continuous passive motion and elevation on hand edema. Am J Occup Ther 1990;44:914-21.

3. Werner GT, Gerhards W, Ingrisch H, Schutte B. Scintigraphy studies of lymph flow in paralyzed upper extremities. Vasa 1997;26: 25-8.

4. Faghri PD. The effects of neuromuscular stimulation-induced muscle contraction versus elevation on hand edema in CVA patients. J Hand Ther 1997;10:29-34.

5. Leibovitz A, Baumoehl Y. Edema of the paretic hand in elderly post-stroke nursing patients. Arch Gerontol and Geriatr 2007;44: $37-42$.

6. Boomkamp-Koppen HG, Visser-Meily JM, Post MW, Prevo AJ. Poststroke hand swelling and oedema: prevalence and relationship with impairment and disability. Clin Rehabil 2005;19:552-9.

7. Post MW, Visser-Meily JM, Boomkamp-Koppen HG, Prevo AJ. Assessment of oedema in stroke patients: comparison of visual inspection by therapists and volumetric assessment. Disabil Rehabil 2003;25:1265-70.

8. Heugten CM. Guideline post-stroke rehabilitation. The Hague: The Netherlands Hartfoundation; 2001;126.

9. Burge E, Kupper D, Finckh A, et al. Neutral functional realignment orthosis prevents hand pain in patients with subacute stroke: a randomized trial. Arch Phys Med Rehabil 2008;89: 1857-62.

10. Gracies JM, Marosszeky JE, Renton R, et al. Short-term effects of dynamic lycra splints on upper limb in hemiplegic patients. Arch Phys Med Rehabil 2000;81:1547-55.

11. Moon AH, Gragnani JA. Cold water immersion for the oedematous hand in stroke patients. Clin Rehabil 1989;3:97-101.

12. Roper TA, Redford S, Tallis RC. Intermittent compression for the treatment of the oedematous hand in hemiplegic stroke: a randomized controlled trial. Age Ageing 1999;28:9-13.

13. Dirette D, Hinojosa J. Effects of continuous passive motion on the edematous hands of two persons with flaccid hemiplegia. Am J Occup Ther 1994;48:403-9. 
14. Meijer JW, Voerman GE, Santegoets KM, Geurts AC. Short-term effects and long-term use of a hybrid orthosis for neuromuscular electrical stimulation of the upper extremity in patients after chronic stroke. J Rehabil Med 2009;41:157-61.

15. Ring H, Rosenthal N. Controlled study of neuroprosthetic functional electrical stimulation in sub-acute post-stroke rehabilitation. J Rehabil Med 2005;37:32-6.

16. Tepperman PS, Greyson ND, Hilbert L, et al. Reflex sympathetic dystrophy in hemiplegia. Arch Phys Med Rehabil 1984;65:442-7.
17. Brand PW. Clinical mechanics of the hand. 2nd ed. St. Louis: C.V. Mosby; 1985.

18. Vasiliauskas R, Dijkers M, Abela MB, Lundgren L. Characteristics in addition to size of the contralateral hand predict hand volume but are not clinically useful. J Hand Ther 1995;8:258-63.

19. Kruitwagen-van Reenen ET, Post MW, Mulder-Bouwens K, VisserMeily JM. A simple bedside test for upper extremity impairment after stroke: validation of the Utrecht Arm/Hand Test. Disabil Rehabil 2009;31:1338-43. 